\title{
Preparation and Characterization of Sustained-Release Naringin Coating on Magnesium Surface
}

\author{
Liting Mu ${ }^{1,2}$, Quan Sun ${ }^{3}$, Gang Cui ${ }^{3}$, Shidan Yuan ${ }^{1}$, Jingyan Wang ${ }^{1}$, Zhen Ma ${ }^{1, *}$ and Muqin Li ${ }^{1, *}$ \\ 1 School of Materials Science and Engineering, Jiamusi University, Jiamusi 154007, China; \\ muliting@163.com (L.M.); jmsdxysd@163.com (S.Y.); jmsdxclwjy@163.com (J.W.) \\ 2 School of Pharmacy, Jiamusi University, Jiamusi 154007, China \\ 3 School of Basic Medicine, Jiamusi University, Jiamusi 154007, China; sunquan2113@163.com (Q.S.); \\ cuigang2072@163.com (G.C.) \\ * $\quad$ Correspondence: mazhen@jmsu.edu.cn (Z.M.); limuqin@jmsu.edu.cn (M.L.); Tel.: +86-454-8618-702 (Z.M.)
}

check for updates

Citation: Mu, L.; Sun, Q.; Cui, G.; Yuan, S.; Wang, J.; Ma, Z.; Li, M. Preparation and Characterization of Sustained-Release Naringin Coating on Magnesium Surface. Coatings 2021, 11, 288. https://doi.org/10.3390/ coatings 11030288

Academic Editor: Kevin Plucknett

Received: 27 January 2021

Accepted: 26 February 2021

Published: 2 March 2021

Publisher's Note: MDPI stays neutral with regard to jurisdictional claims in published maps and institutional affiliations.

Copyright: (c) 2021 by the authors. Licensee MDPI, Basel, Switzerland. This article is an open access article distributed under the terms and conditions of the Creative Commons Attribution (CC BY) license (https:/ / creativecommons.org/licenses/by/ $4.0 /)$.

\begin{abstract}
Given the three-dimensional multi-level structure of natural bone and the multi-factor time-shifting effect in the healing process after bone trauma, there are plans to introduce drugcontrolled release systems into the treatment of orthopedic diseases. To achieve multi-level loading and controlled release of biologically active substances, it is necessary to create synergistic behavior between biological factors, thereby improving the bone regeneration ability of artificial bone replacement materials. A naringin-loaded (NG) coating was prepared, compared with ultrasonic micro-arc oxidation (UMAO). The coating was characterized by X-ray diffraction, infrared spectroscopy, and scanning electron microscopy. The corrosion resistance of the coating was studied through the wetting angle and polarization curve. The high-performance liquid chromatography method was used to test the release of the drug. It can be seen from the experimental results that the NG coating has a larger wetting angle and better corrosion resistance. In addition, the NG coating produces more apatite substances and has good biological activity. The NG coatings can stimulate the natural bone regeneration and repair process by releasing drugs during the process, which can effectively promote bone regeneration and repair after implantation in the body.
\end{abstract}

Keywords: pure magnesium; ultrasonic micro-arc oxidation; sustained release; naringin

\section{Introduction}

With the continuous advancement of medical technology, new metal materials, such as degradable metals and nanocrystalline metals, are being tested for their use as orthopedic implant materials. These materials are progressing from biologically inert ones to ones with biologically functionalization [1-3]. Magnesium (Mg) and its alloys have been in the focus of investigation as a potential degradable endophyte material and bone defect repair material because of several material properties [4,5]. First of all, the material is known to be spontaneously degradable and non-toxic [6]. In addition, magnesium and its alloys have excellent biological safety [7]. Mg participates in a variety of metabolism in the organism, including regulating bone metabolism and inducing new bone formation [8].

However, the low potential of magnesium and its alloys leads to excessive degradation in the physiological environment, and the $\mathrm{pH}$ rises around the implant, resulting in unmanageable air cavity, inflammation, infection, and other complications, which cannot meet the requirements of implant materials in vivo [9-13], thereby reducing the biological safety and compatibility of implant materials. Therefore, in order to improve the degradation rate of magnesium-based materials, match the rate of bone healing and ensure its good biocompatibility. At present, the degradation rate of magnesium and its alloys is mainly through the alloying and surface modification of magnesium. Rzycho' has made WE43 alloy stents and screws, which have been successfully applied in the human body [14]. Yan treated AZ31B magnesium alloy with fluorine, and the degradation performance of AZ31B 
after fluoride treatment could meet the requirements of biodegradable materials [15]. Yan prepared rare earth conversion coating on AZ31B magnesium alloy, which had good corrosion resistance and good anticoagulant performance [16]. Lu prepared biologically active strontium containing $\mathrm{Ca}-\mathrm{P}$ coating, for which the corrosion rate was significantly reduced, and the formation of apatite was increased [17]. However, another challenge in medicine is how to control the rate of hydrogen generated during the degradation of the alloy and avoid the generation of a large amount of gas accumulation. In order to further reduce the corrosion rate of magnesium and its alloys, materials workers have studied many magnesium surface modifications. Höhlinger has prepared bio-functional chitosan bio-active glass coating on WE43 magnesium alloy through the electrophoretic deposition method: the sample did not suffered any corrosion erosion, and the bio-active glass particles were very uniformly distributed [18]. Golshirazi used self-assembly technology to prepare a coating on the surface of AZ91 alloy to improve corrosion resistance [19].

The challenge of using alternative methods of surface modification is that during the replacement process, severe corrosion and hemolysis will occur around the magnesium implant. Therefore, the preparation of composite coating on the surface of magnesium alloy may be needed, and an optimum pre-treatment should regulate the degradation rate of magnesium and its alloys during the coating process, enable good biocompatibility, antibacterial, anti-inflammatory, and other properties to the coating, and enable good bonding of magnesium matrix to the surface and to the coating.

Ultrasonic micro-arc oxidation (UMAO) is a universal material surface modification technology, based on the adjustment of electrolyte and electrical parameter, where discharge generates instantaneous high temperature and high pressure, forming a modified ceramic coating of base metal oxide [20]. The ceramic coating is prepared by the UMAO technology. Polylactic acid/glycolic acid copolymer (PLGA) was widely used in biological materials due to its controllable degradation characteristics. First of all, the PLGA is non-toxic and has strong hydrophobicity [21-23]. In addition, PLGA has adjustable degradation performance and biocompatibility. Li prepared a PLGA coating on the surface of a magnesium-zinc alloy, and evaluated the corrosion resistance of the coating using electrochemical impedance spectroscopy and polarization curves. The results showed that PLGA coating improves the corrosion resistance of $\mathrm{Mg}-\mathrm{Zn}$ alloy [24]. Zeng prepared a silver/PLGA coating, in vitro and in vivo, for the analysis of bacterial colonization and three-dimensional computed tomography scanning analysis. The research indicates that Ti implants have simultaneous antimicrobial and osteoinductive activities [25]. Naringin (NG) has unique biological and pharmacological activities, which can promote the growth of osteoblasts, and reduce inflammation. Cai found that NG could increase the bone mineral density and mechanical properties of the femur of ovariectomized osteoporotic rats, and improved the microstructure of trabecular bone [26]. Nilamber proved through experiments that topical NG had a protective effect on cell apoptosis. NG could inhibit the absorption of bone by osteoclasts and reduce inflammation, and it could promote the proliferation of endothelial progenitor cells and was beneficial to wound recovery [27]. However, few reports focused on combining PLGA with NG to form a coating to modify the biological activity of magnesium. In this artilcle, the PLGA sustained-release NG drug coating was prepared on the UMAO pure magnesium coating by the self-assembly method, and the structure was characterized, using electrochemistry and simulated body fluid immersion for comprehensive evaluation.

\section{Materials and Methods}

\subsection{Preparation of the Coating}

The $1 \mathrm{~mm}$ pure $\mathrm{Mg}$ (content greater than 99.9\%) test plate was processed into a sample with a size of $15 \times 15 \mathrm{~mm}$ by wire cutting. The samples were prepared into a smooth surface with 1000-2000 mesh SiC sandpaper, and then ultrasonically cleaned with 75\% ethanol to clean, and then rinsed with deionized water to clean the surface. The sample is cleaned using $80 \mathrm{~g} / \mathrm{L} \mathrm{NaHCO}_{3}$ solution and $100 \mathrm{~g} / \mathrm{L} \mathrm{H}_{3} \mathrm{PO}_{4}$ solution to clean the sample 
to remove oil rust and $\mathrm{MgO}$, followed by ultrasonic cleaning with deionized water, and dry storage in a dry box. The working parameters for the micro-arc oxidation treatment are as follows: first, a voltage of $300 \mathrm{~V}$, frequency of $500 \mathrm{~Hz}$, pulse width of $50 \mu \mathrm{s}$, and oxidation $7 \mathrm{~min}$; second, a regulated voltage of $260 \mathrm{~V}$, frequency of $500 \mathrm{~Hz}$, pulse width of $50 \mu \mathrm{s}$, and oxidation time of $3 \mathrm{~min}$. To prepare sustained-release NG solution: $500 \mathrm{mg}$ PLGA (50:50) and $30 \mathrm{mg}$ NG are dissolved in $10 \mathrm{~mL}$ of dichloromethane, and sonicated for $5 \mathrm{~min}$ to make it fully dissolved. Then, the micro-arc oxidation sample was immersed in a slow-release Chinese medicine solution for $3 \mathrm{~min}$. Then the sample was taken out and hung in the air to dry.

\subsection{Coating Characterization}

\subsubsection{Phase Structure of the Coating}

The phase composition of different Chinese medicine-loaded coatings was analyzed by using an X-ray diffractometer (XRD, D8-ADVANCE, BRUKER, Karlsruhe, Germany). X-ray diffractometer test parameters were: working voltage $40 \mathrm{~V}$, working current $30 \mathrm{~mA}$, copper target $\mathrm{K} \alpha$ radiation, $2 \theta$ scanning range is $10^{\circ}-90^{\circ}$, scanning speed is $2^{\circ} / \mathrm{min}$, step length is $0.02^{\circ}$, and grazing incidence angle is $1^{\circ}-4^{\circ}$. After spraying gold on the surface of different Chinese medicine-loaded coatings and simulated body fluid treatments, the surface and cross-sectional morphology of the coatings were observed by scanning electron microscope (SEM, JSM-7800JJEOL, Tokyo, Japan). The elements of the different drug-containing coatings were analyzed by energy dispersive spectroscopy (EDAX, FALCON60S, Mahwah, NJ, USA). A Fourier infrared spectrometer (FT-IR) (VECTOR33, Karlsruhe, Germany) was used to analyze the surface characteristics of different drug-loaded composite coatings. And use X-ray photoelectron spectroscopy (XPS, ESCALAB250XI, Thermo Fisher Scientific, Waltham, MA, USA) was used to detect the surface adsorption of elements on the surface of different coatings, as well as the energy band structure, chemical structure, and chemical bond. X-ray photoelectron spectroscopy test parameters were: working power $300 \mathrm{~W}$, excitation source is $\mathrm{Al} \mathrm{K} \alpha, \mathrm{C} 1 \mathrm{~s}$ (binding energy $284.8 \mathrm{eV}$ ) is used to correct element charge potential before detection, and fit the peaks of high-resolution XPS spectra.

\subsubsection{Immersion Tests}

Apatite induced by the simulated body fluid (SBF) immersion experiment is an important indicator of biological activity of biological materials. The prepared Chinese medicine-loaded coatings were subjected to simulated body fluid immersion experiments. SBF [28] composition is showen in Table 1. The test temperature was $37.0 \pm 0.5^{\circ} \mathrm{C}$, and after immersion for 3, 7, and 14 days, it was rinsed and dried in deionized water and dried to detect the surface morphology and phase composition of the sample.

Table 1. Chemical composition and reagents' grade and purity used for preparation of simulated body fluid (SBF).

\begin{tabular}{cccccc}
\hline No. & $\begin{array}{c}\text { Chemical } \\
\text { Formula }\end{array}$ & Amount & Reagent Grade & Purity & Manufacturer \\
\hline 1 & $\mathrm{NaCl}$ & $8.035 \mathrm{~g} / \mathrm{L}$ & ACS reagent & $\geq 99.9 \%$ \\
2 & $\mathrm{NaHCO}_{3}$ & $0.355 \mathrm{~g} / \mathrm{L}$ & Bio Reagent & $\geq 99.5 \%$ \\
3 & $\mathrm{KCl}$ & $0.225 \mathrm{~g} / \mathrm{L}$ & ACS reagent & $\geq 99.5 \%$ & \\
4 & $\mathrm{~K}_{2} \mathrm{HPO}_{4} 3 \mathrm{H}_{2} \mathrm{O}$ & $0.231 \mathrm{~g} / \mathrm{L}$ & ACS reagent & $\geq 99.9 \%$ & Comeo Co., Ltd., \\
5 & $\mathrm{MgCl}_{2} 6 \mathrm{H}_{2} \mathrm{O}$ & $0.311 \mathrm{~g} / \mathrm{L}$ & ACS reagent & $\geq 98.0 \%$ & Tianjin, China \\
6 & $1.0 \mathrm{M}-\mathrm{HCl}_{7}$ & $39 \mathrm{~mL}$ & ACS reagent & $\geq 37.0 \%$ & $\geq 99.9 \%$ \\
8 & $\mathrm{CaCl}_{2}$ & $0.292 \mathrm{~g} / \mathrm{L}$ & ACS reagent & $\geq 99.9 \%$ & \\
9 & $\mathrm{Na}_{2} \mathrm{SO}_{4}$ & $0.072 \mathrm{~g} / \mathrm{L}$ & ACS reagent & $\geq 99.9 \%$ & \\
\hline
\end{tabular}

\subsubsection{Electrochemical Tests}

Electrochemical impedance spectroscopy (EIS) and polarization curves of different drug-loaded coating samples were tested using VersaSTAT 3 electrochemical workstation to evaluate the corrosion resistance of the coating and analyze the corrosion mechanism of 
different coatings. Three-electrode system: the platinum sheet is the counter electrode, the saturated calomel electrode is the reference electrode, the sample is the working electrode, the simulated body fluid is the test medium, and the open circuit potential is tested. Potential dynamics polarization test parameters: $-500 \mathrm{mV}-500 \mathrm{mV}$, and scanning speed is $1.0 \mathrm{mV} / \mathrm{s}$. EIS measurement range: $10^{4}-10^{-1} \mathrm{~Hz}$. ZsimpWin 3.30 software was used to perform equivalent circuit fitting of impedance results.

\subsubsection{Slow-Release Drug Measurement}

The drug release concentration was tested by a high-performance liquid chromatograph (Agilent 1200, Agilent Technologies, Santa Clara, CA, USA) using the following conditions: the column was an Agilent SB-C $18(250 \times 4.6 \mathrm{~mm}, 5 \mu \mathrm{m}$, Agilent Technologies, Santa Clara, CA, USA) the mobile phase was methanol-0.1\% acetic acid water (50:50), and the detection wavelength was $283 \mathrm{~nm}$. To detect the NG content of UMAO/PLGA/NG coating in SBF solution.

\section{Results and Discussion}

\subsection{Characterization of the Different Coatings}

Figure 1 shows the XRD patterns of different coatings. UMAO, UMAO/PLGA, and $\mathrm{UMAO} / \mathrm{PLGA} / \mathrm{NG}$ coatings were composed of $\mathrm{Mg}$ (ICDD file number 35-0822), $\mathrm{MgO}$ (ICDD file number 65-0475), and $\mathrm{Mg}_{2} \mathrm{SiO}_{4}$ (ICDD file number 83-1806) [29,30].

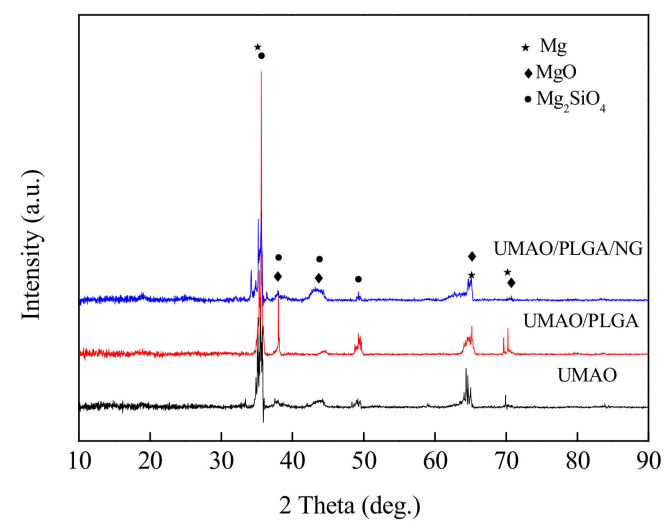

Figure 1. X-ray diffraction (XRD) of different coatings.

Figure 2 shows the FT-IR spectra of different coatings. At $424 \mathrm{~cm}^{-1}$, typical Mg-O tensile vibration was seen [31]. At 903 and $1022 \mathrm{~cm}^{-1}$, there were $\mathrm{SiO}_{4}{ }^{2-}$ stretching vibration peaks [32]. For the infrared spectrum curve of the UMAO/PLGA coating, PLGA showed three characteristic bands [33]. The $\mathrm{C}-\mathrm{H}$ vibration peak is displayed at $520 \mathrm{~cm}^{-1}$, and the peak of the $\mathrm{C}=\mathrm{O}$ bond is displayed at $1778 \mathrm{~cm}^{-1}$, and at $3702 \mathrm{~cm}^{-1}$ is the result of the left shift of the hydroxyl stretching vibration peak in the PLGA structure molecule [34]. The broad and strong absorption peak at $3420 \mathrm{~cm}^{-1}$, which is the peak of $-\mathrm{OH}$, the peak of the carbonyl group at $1580 \mathrm{~cm}^{-1}$, and the peak at $1370 \mathrm{~cm}^{-1}$ are the benzene ring skeleton and the benzene ring. For double bond, the peak at $1150 \mathrm{~cm}^{-1}$ is supposed to be the structure of $\mathrm{C}-\mathrm{O}-\mathrm{C}[35,36]$. 


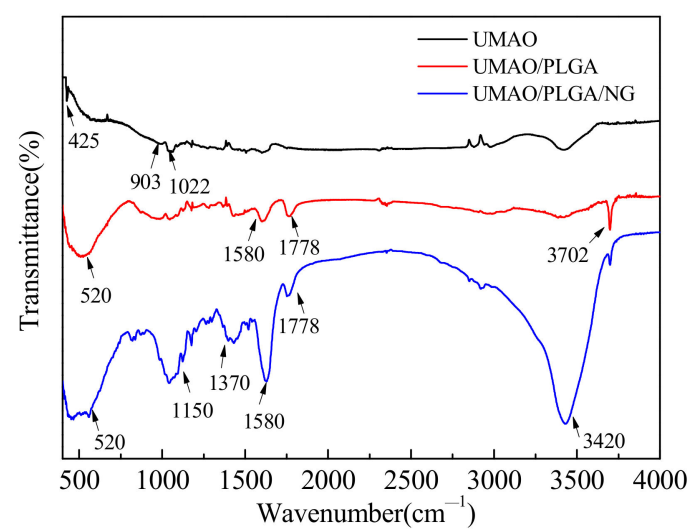

Figure 2. Fourier transform infrared spectrograph (FT-IR) spectra of different coatings.

\subsection{Coating Surface Morphology}

Figure 3 shows the SEM image of the surface morphology of different coatings. Figure 3 a shows the surface morphology of UMAO, which had a typical irregular porous structure. However, the honeycomb structure and pores on the surface of the UMAO/PLGA coating were small, indicating that the PLGA coating loaded onto the surface of the microarc oxidation coating had a good sealing effect. The UMAO/PLGA/NG coating could also seal the pores in the UMAO coating, and the surface of the NG coating was rougher, which was more conducive to the adhesion and growth of bone cells.
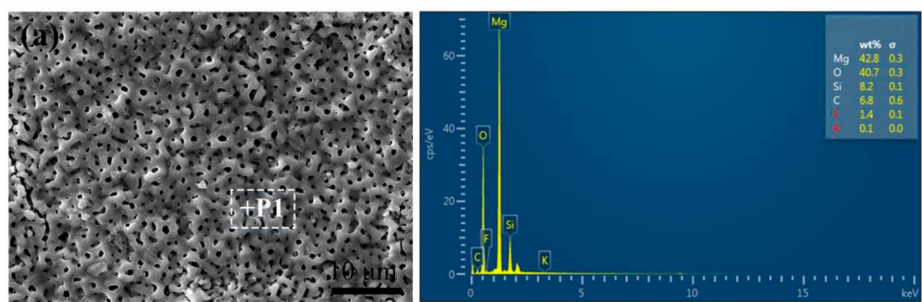

(b)
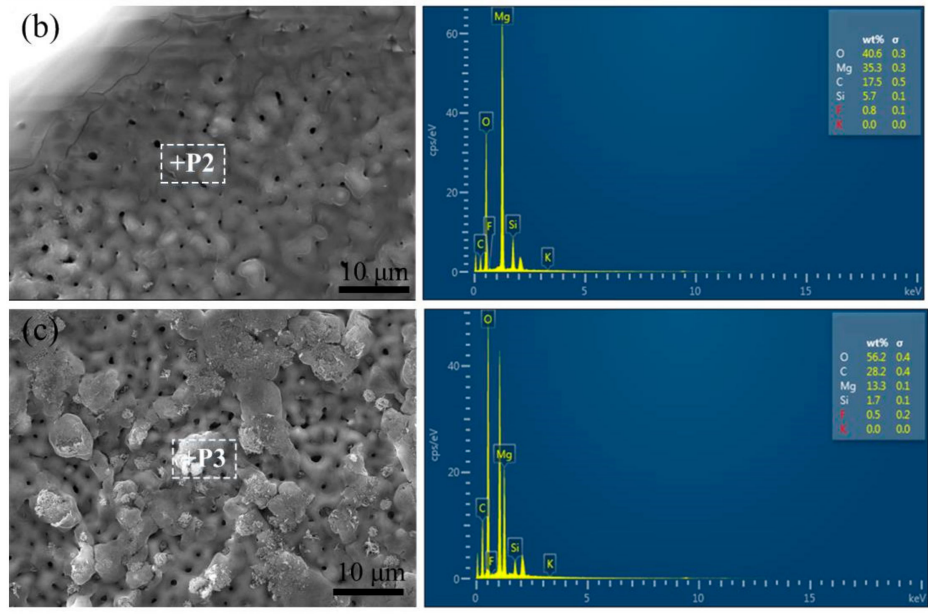

Figure 3. Scanning electron microscopy (SEM) images of the different coatings: (a) UMAO, (b) UMAO/PLGA, and (c) UMAO/PLGA/NG.

\subsection{XPS Analysis}

Figure 4 showS the XPS analysis of different coatings. The UMAO coating produced $\mathrm{Mg}, \mathrm{C}, \mathrm{O}$, and $\mathrm{Si}$ spectral peaks, while the UMAO/PLGA and UMAO/PLGA/NG coatings primarily produced those of $C$ and $O$. This is consistent with the coating surface morphologies. Figure $4 \mathrm{~b}$ illustrates the Mg $1 \mathrm{~s}$ XPS spectrum of the UMAO coating. At binding energy $1303.7 \mathrm{eV}, \mathrm{Mg} 1 \mathrm{~s}$ was found in the UMAO coating. The fitted peaks appear 
at $1303.9 \mathrm{eV}$ and $1304.9 \mathrm{eV}$, which are correspond to the existence of $\mathrm{Mg}$ and $\mathrm{MgO}$ in the coating. Figure $4 \mathrm{c}$ shows the $\mathrm{O} 1 \mathrm{~s}$ pattern of the UMAO coating, where the binding energies of $\mathrm{MgO}$ and $\mathrm{Mg}_{2} \mathrm{SiO}_{4}$ are $531.6 \mathrm{eV}$ and $536.6 \mathrm{eV}$, respectively [37]. For $\mathrm{Si} 2 \mathrm{p}$, the spectrum contained two $\mathrm{Mg}_{2} \mathrm{SiO}_{4}$ peaks: one at $101.9 \mathrm{eV}$ for $\alpha-\mathrm{Mg}_{2} \mathrm{SiO}_{4}$, and the other at $102.5 \mathrm{eV}$ for $\gamma-\mathrm{Mg}_{2} \mathrm{SiO}_{4}$ [38]. Figure $4 \mathrm{e}-\mathrm{g}$ illustrated the $\mathrm{C}, \mathrm{O}$, and $\mathrm{Si}$ XPS spectra for the PLGA coating, respectively. In Figure 4e, the fitted peaks that appear at 289.1, 287.1, $286.8,285.2,284.6$, and $284.5 \mathrm{eV}$ correspond to the COOR, C-O, C=O, C-C, C-H, and $\mathrm{C}=\mathrm{C}$ functional groups, respectively. This is consistent with the structure of carbon present in PLGA [39,40]. In Figure 4f, the $\mathrm{O}$ 1s pattern of the PLGA coating is fitted to 3 peaks that correspond to $-\mathrm{OH}(531.9 \mathrm{eV}), \mathrm{O}-\mathrm{C}=\mathrm{O}(533.2 \mathrm{eV})$, and $\mathrm{C}-\mathrm{O}(532.7 \mathrm{eV})$, indicating the formation of a PLGA coating [41,42]. Figure $4 \mathrm{~g}$ illustrates the Si 2p XPS spectra of the PLGA coating. Because the surface is covered with the PLGA coating, the binding energy intensity of the Si $2 p$ XPS spectrum is very low. Figure 4 h,i show the XPS spectra of $C$ 1s and $\mathrm{O} 1 \mathrm{~s}$ in the UMAO/PLGA/NG coating. No Si $2 \mathrm{p}$ absorption peaks were seen (Figure $4 \mathrm{a}$ ), and therefore they are not listed. The $\mathrm{C} 1$ s spectrum exhibited six peaks for $\mathrm{RO}-\mathrm{C}=\mathrm{O}$ (286.4 eV), C $-\mathrm{O}(287.0 \mathrm{eV}), \mathrm{C}=\mathrm{C}(285.2 \mathrm{eV}), \mathrm{C}-\mathrm{H}(284.6 \mathrm{eV}), \mathrm{C}=\mathrm{O}(286.8 \mathrm{eV})$, and $\mathrm{C}=\mathrm{C}$ $(284.5 \mathrm{eV})[39,40]$. In Figure 4i, the $\mathrm{O} 1 \mathrm{~s}$ spectrum exhibits three peaks for $-\mathrm{OH}(531.9 \mathrm{eV})$, $\mathrm{C}-\mathrm{O}(532.5 \mathrm{eV})$, and $\mathrm{O}-\mathrm{C}=\mathrm{O}(533.6 \mathrm{eV})[41,42]$. Due to the addition of $\mathrm{NG}$, the area of the three peaks in the $\mathrm{C} 1 \mathrm{~s}$ spectrum changed. NG contains many $\mathrm{C}-\mathrm{O}$ and $\mathrm{C}=\mathrm{O}$ functional groups. Therefore, the peak area fitted by $\mathrm{C}-\mathrm{O}$ and $\mathrm{C}=\mathrm{O}$ in the $\mathrm{O} 1 \mathrm{~s}$ and $\mathrm{C} 1 \mathrm{~s}$ spectra of the UMAO/PLGA/NG coating was high, and the peak area of $\mathrm{RO}-\mathrm{C}=\mathrm{O}$ was the largest in the $\mathrm{C} 1 \mathrm{~s}$ spectrum. In the $\mathrm{C} 1$ s spectrum of the PLGA coating, $\mathrm{O}-\mathrm{C}=\mathrm{O}$ occupied a small area. Therefore, when the NG was added to the PLGA coating, it primarily associated with the PLGA in the form of an ester bond or dehydrated into a bond when forming the coating, resulting in a stable coating.
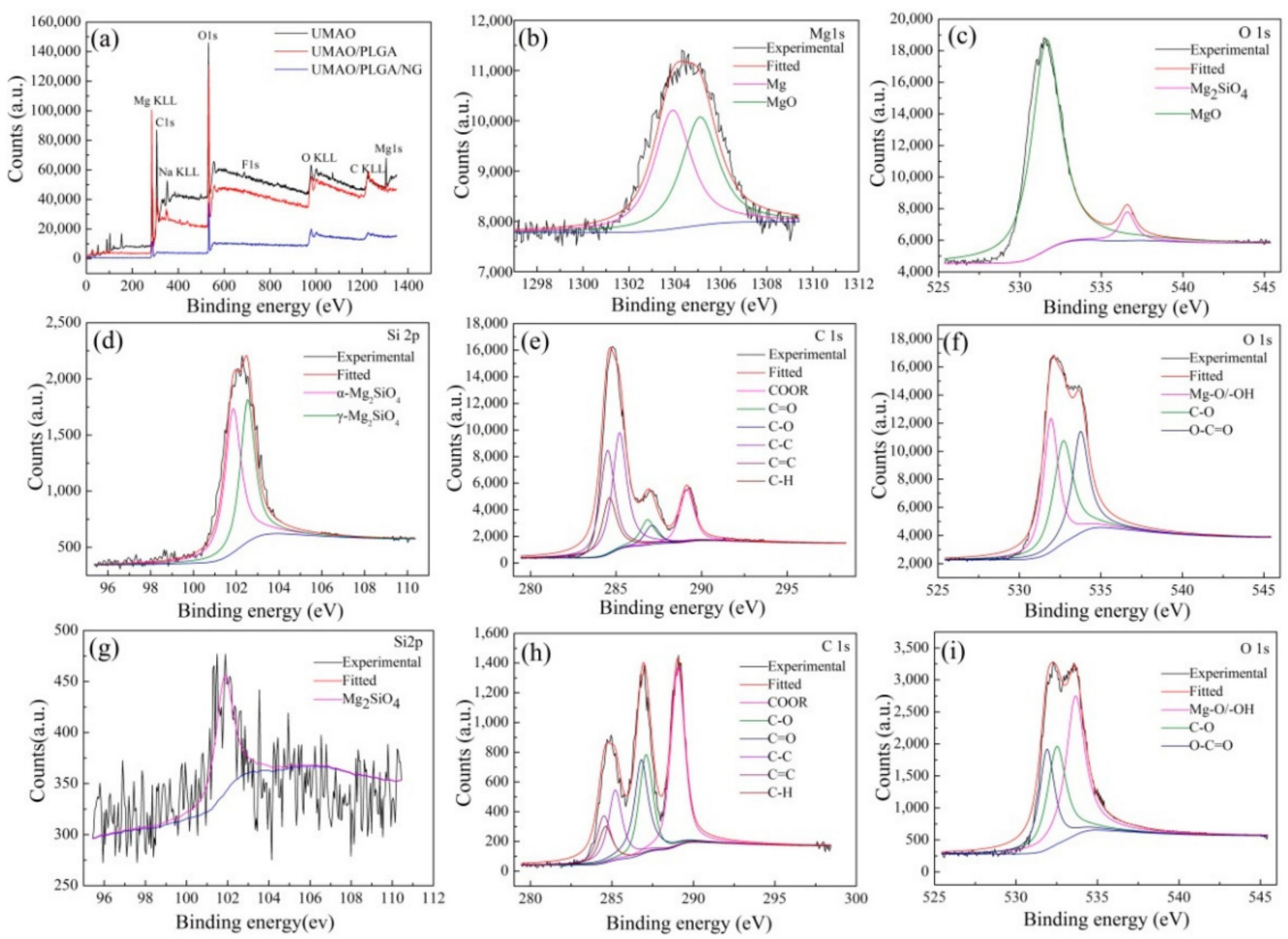

Figure 4. (a) XPS spectrum of the different coatings, (b-d) detailed XPS spectra of the Mg 1s, O 1s, and Si 2p for the UMAO coating, respectively, (e-g) detailed XPS spectra of the C 1s, O 1s, and Si 2p for the UMAO/PLGA coating, respectively; and $(h, i)$ detailed XPS spectra of the $\mathrm{C} 1 \mathrm{~s}$ and $\mathrm{O}$ 1s for the UMAO/PLGA/NG coating, respectively. 


\subsection{SBF Immersion Test}

Figure 5 shows the distribution of elements from spot-sweeps of the UMAO/PLGA/NG coatings in SBF for $0,3,7$, and 14 days. Table 2 gives the elemental composition of the $\mathrm{UMAO} / \mathrm{PLGA} / \mathrm{NG}$ coatings in SBF for different periods of time obtained by energy spectrum analysis of the surface spot scans. It can be seen from Table 2, that in addition to the original $\mathrm{O}, \mathrm{Mg}, \mathrm{Si}$, and $\mathrm{C}, \mathrm{Ca}$ and $\mathrm{P}$ appeared in the surface of the coating. The amounts of $\mathrm{Ca} / \mathrm{P}$ in the coatings after 3,7 , and 14 days were $1.17,1.47$, and 1.19 , respectively. This shows that during the immersion process, the $\mathrm{Ca}^{2+}$ and $\mathrm{PO}_{4}{ }^{3-}$ plasmas in the SBF reacted with the coating to form a new compound, hydroxyapatite (HA). In addition, as the immersion time increased, $\mathrm{Ca}$ and $\mathrm{P}$ were concentrated on the coating, and the atomic ratio of $\mathrm{Ca} / \mathrm{P}$ gradually increases, and the $\mathrm{Ca} / \mathrm{P}$ atomic ratio gradually increased.
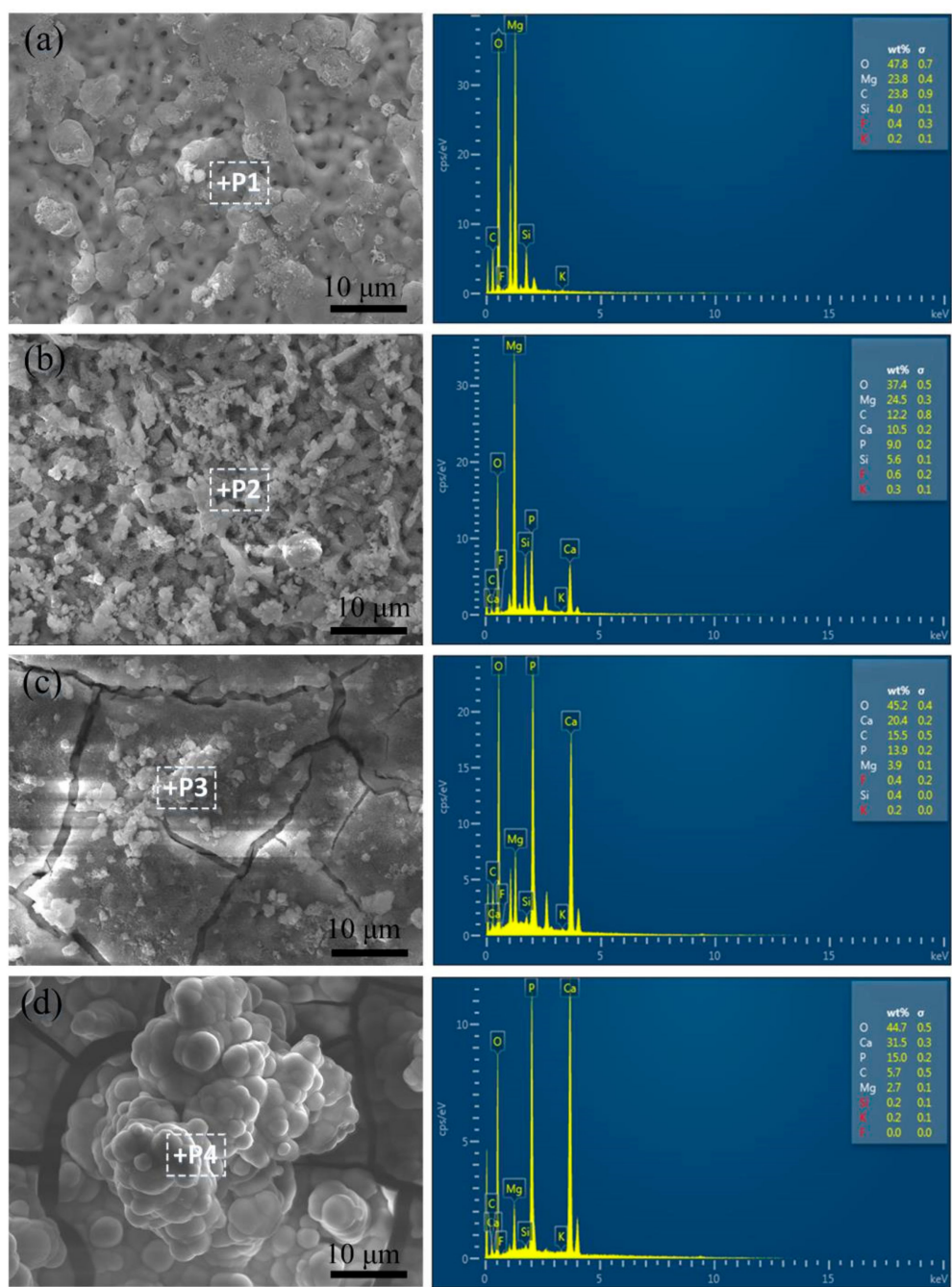

Figure 5. SEM micrographs of the UMAO/PLGA/NG coating in SBF for (a) 0, (b) 3, (c) 7, and (d) 14 days.

Table 2. Elemental composition of the UMAO/PLGA/NG coating in SBF.

\begin{tabular}{cccccccc}
\hline Days & O (\%) & Mg (\%) & C (\%) & Si (\%) & Ca (\%) & P (\%) & Ca/P \\
\hline 0 & 47.8 & 23.8 & 23.8 & 4.0 & 0 & 0 & 0 \\
3 & 37.4 & 24.5 & 12.2 & 5.6 & 10.5 & 9.0 & 1.17 \\
7 & 45.2 & 3.9 & 15.5 & 0.4 & 20.4 & 13.9 & 1.47 \\
14 & 44.7 & 2.7 & 5.7 & 0.2 & 31.5 & 15.0 & 2.1 \\
\hline
\end{tabular}




\subsection{Corrosion Resistance}

The polarization curves of different coatings are shown in Figure 6. The corrosion current density $\left(I_{\text {corr }}\right)$ and corrosion potential $\left(E_{\text {corr }}\right)$ values are summarized in Table 3 . Compared with the UMAO coating, the corrosion potential of the UMAO/PLGA coating shifted positively, and the $I_{\text {corr }}$ decreased from $2.53 \times 10^{-6} \mathrm{~A} / \mathrm{cm}^{2}$ (UMAO) to $1.74 \times 10^{-7} \mathrm{~A} / \mathrm{cm}^{2}$ (UMAO/PLGA). For the UMAO/PLGA coating, the corrosion current density of the substrate was reduced by nearly an order of magnitude. In addition, the corrosion current density of the UMAO/PLGA/NG coating was lower than the UMAO/PLGA coating, which indicates that the composite coating was more effective in preventing the rapid corrosion of magnesium in the initial stage. There have been few reports on the effect of NG on corrosion resistance, but the experimental results showed that the corrosion resistance of the film after adding NG was improved.

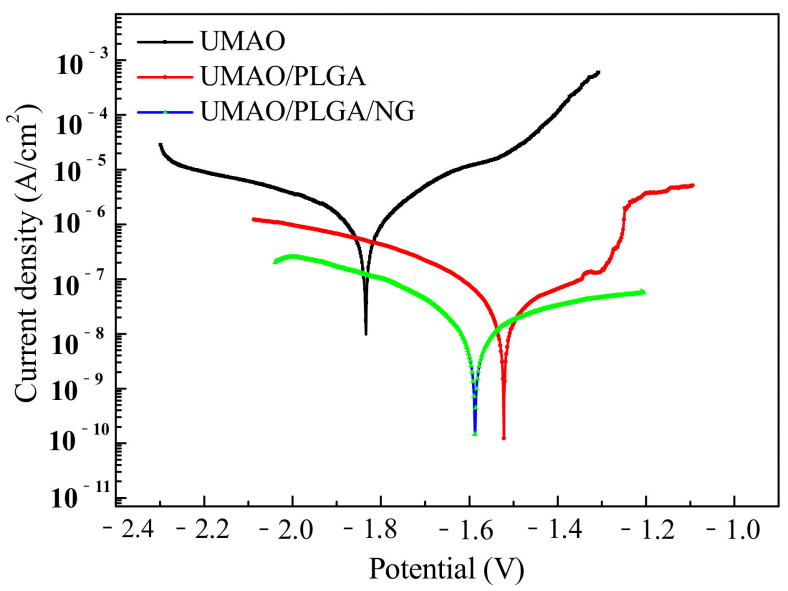

Figure 6. Polarization curves of different coatings.

Table 3. Corrosion current densities and corrosion potentials for different coatings.

\begin{tabular}{cccc}
\hline Sample & UMAO & UMAO/PLGA & UMAO/PLGA/NG \\
\hline Open $E_{\text {corr }}(\mathrm{V})$ & -1.827 & -1.546 & -1.565 \\
$E_{\text {corr }}(\mathrm{V})$ & -1.829 & -1.513 & -1.573 \\
$I_{\text {corr }}\left(\mathrm{A} / \mathrm{cm}^{2}\right)$ & $2.53 \times 10^{-6}$ & $1.74 \times 10^{-7}$ & $3.6 \times 10^{-8}$ \\
\hline
\end{tabular}

The Nyquist plots of different coatings are shown in Figure 7a. The experimental data is represented by symbols, and the fitted data is represented by solid lines. Compared with the UMAO coating, the capacitance circuits of the UMAO/PLGA/NG coating increased, indicating that they have a higher corrosion resistance. The UMAO coating was composed of a wide capacitive loop and an inductive loop. The capacitive loop in the high frequencies indicates the resistance and capacitance of the corrosive medium through the pores of the UMAO coating. The inductive loop in the low frequencies indicates the coating layer destruction or release of adsorbate. The UMAO coating had a resistance loop at low frequencies, indicating that the protective ability of this coating is poor. The UMAO/PLGA coating was composed of a capacitive reactance loop and an inductive reactance loop. The high-frequency capacitive reactance represents the resistance and capacitance across the PLGA layer, and the intermediate frequency capacitive reactance represents the resistance and capacitance across the UMAO layer. The UMAO/PLGA/NG coating was composed of two capacitive reactance loops at high and intermediate frequencies. The capacitive reactance loop in the high frequencies corresponds to the resistance and capacitance passing through the PLGA/NG layer. The UMAO/PLGA and UMAO/PLGA/NG coatings did not show inductive resistance loops at low frequencies, indicating that these two coatings have strong protective capabilities. 

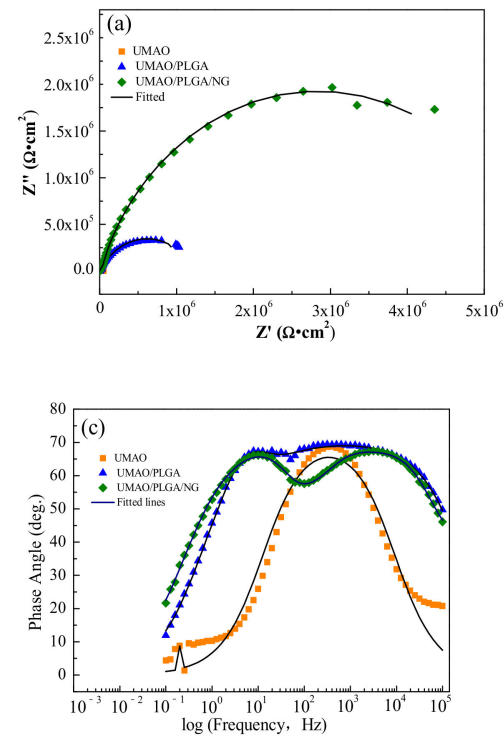

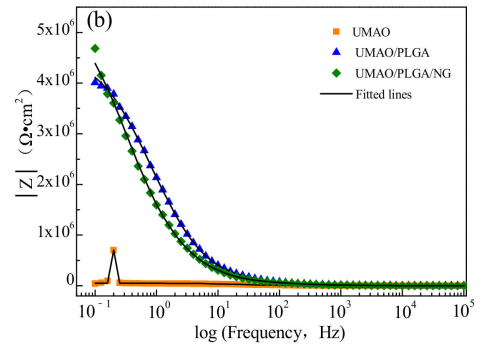

(d)

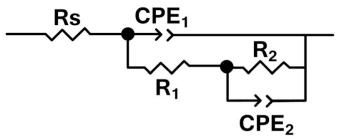

Figure 7. (a) Nyquist plots, (b,c) Bode plots, and (d) equivalent circuit of the different coatings.

The Bode and fitting plots of the UMAO, UMAO/PLGA, and UMAO/PLGA/NG coatings are shown in Figure $7 \mathrm{~b}$. There are two time-constants in the UMAO coating, which respond to UMAO coating and substrate magnesium, respectively. The UMAO/PLGA and UMAO/PLGA/NG coatings have similar Bode plots. The low-frequency and highfrequency time constants are the response of the UMAO and PLGA layers, respectively. The coating of the traditional Chinese medicine NG showed no response to the electrochemical process of the pure magnesium surface, that is, the SBF did not erode the substrate, and its impedance modulus was much higher than that of the UMAO coating. It can be seen that the UMAO/PLGA/NG coating on the substrate performed very well as a protective coating.

The phase angle of the UMAO, UMAO/PLGA, and UMAO/PLGA/NG coatings are shown in Figure 7c. The phase angle produced by the UMAO/PLGA/NG coating was the largest, while the UMAO/PLGA and UMAO coatings were relatively small. A larger phase angle indicates a stronger corrosion resistance. Therefore, the UMAO/PLGA/NG coating provided a good barrier to corrosive media.

The equivalent circuit of the UMAO/PLGA/NG coating is shown in Figure $7 \mathrm{~d}$. In the circuit, $\mathrm{Rs}$ is the solution resistance, $\mathrm{CPE}_{2}$ represents the capacitance of the UMAO layer, $\mathrm{R}_{2}$ represents the resistance of the UMAO layer, $\mathrm{CPE}_{1}$ represents the capacitance of the PLGA/NG layer, and $R_{1}$ represents the resistance of the PLGA/NG layer. The smaller the capacitance and the larger the impedance value, the more corrosion-resistant the sample $[20,43]$.

The fitting data is shown in Table 4 , where the $\mathrm{R}_{1}$ values of the UMAO coating were lower than that of the UMAO/PLGA and UMAO/PLGA/NG coatings, and the $\mathrm{CPE}_{1}$ values of the UMAO/PLGA and UMAO/PLGA/NG coatings were lower than that of the UMAO coating, indicating that the surface had a strong ability to inhibit charge transfer. The results show that the UMAO/PLGA/NG coating has good corrosion resistance.

Table 4. Values of the equivalent circuit parameters for the different coatings.

\begin{tabular}{|c|c|c|c|c|c|}
\hline Sample & $\begin{array}{c}\text { Rs } \\
\left(\Omega \cdot \mathrm{cm}^{2}\right)\end{array}$ & $\begin{array}{c}\mathrm{CPE}_{1} \\
\left(\mathrm{~F} \cdot \mathrm{cm}^{2}\right)\end{array}$ & $\begin{array}{c}R_{1} \\
\left(\Omega \cdot \mathrm{cm}^{2}\right)\end{array}$ & $\begin{array}{c}\mathrm{CPE}_{2} \\
\left(\mathrm{~F} \cdot \mathrm{cm}^{2}\right)\end{array}$ & $\begin{array}{c}R_{2} \\
\left(\Omega \cdot \mathrm{cm}^{2}\right)\end{array}$ \\
\hline UMAO & 257.6 & $5.40 \times 10^{-7}$ & $5.28 \times 10^{4}$ & $1.20 \times 10^{-7}$ & $7.96 \times 10^{5}$ \\
\hline UMAO/PLGA & 160.6 & $8.79 \times 10^{-8}$ & $1.52 \times 10^{6}$ & $6.02 \times 10^{-8}$ & $4.49 \times 10^{6}$ \\
\hline UMAO/PLGA/NG & 124.6 & $1.23 \times 10^{-8}$ & $1.26 \times 10^{6}$ & $1.39 \times 10^{-9}$ & $1.69 \times 10^{7}$ \\
\hline
\end{tabular}




\subsection{Slow-Release Drug Measurements}

According to the in vitro simulation experiment detailed in the "slow-release drug measurement" method, a curve was established describing the cumulative release rate over time, as shown in Figure 8. The cumulative release of NG from the UMAO/PLGA/NG coating reached $91.34 \%$ after soaking in the SBF solution for 20 days. This indicates that, in the early stage of bone injury, the coating can slowly release bone growth-promoting drugs for one month, which is of great significance for accelerating bone growth in the early stage of a bone injury.

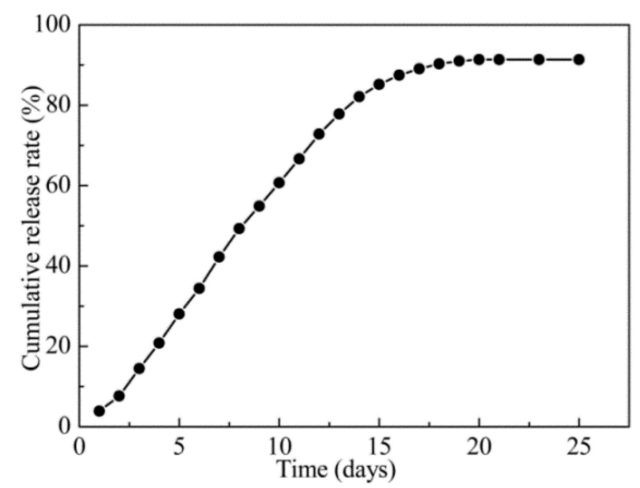

Figure 8. Cumulative release curve of the UMAO/PLGA/NG coating.

\section{Conclusions}

Three coatings (UMAO, UMAO/PLGA and UMAO/PLGA/NG) were prepared in this experiment, and the corrosion behavior and biological activity of different coatings were studied. XRD results showed that the three coatings were composed of $\mathrm{Mg}, \mathrm{MgO}$, and $\mathrm{Mg}_{2} \mathrm{SiO}_{4}$. XPS results showed that when the NG was added to the PLGA coating, it was primarily associated with the PLGA in the form of an ester bond or dehydrated into a bond when forming the coating, resulting in a stable coating. After SBF soaking, the UMAO/PLGA/NG coating formed more hydroxyapatite. The electrochemical results showed that the corrosion current of the UMAO/PLGA/NG coating was $3.6 \times 10^{-8}$, which was two orders of magnitude lower than the UMAO coating, indicating it had better corrosion resistance. The drug was sustained in vitro for up to 20 days. Compared with UMAO and UMAO/PLGA coatings, the UMAO/PLGA/NG coating had better corrosion resistance and bioactivity. This development of biological functionalization has many potential applications.

Author Contributions: Data analysis and chart making, Q.S. and Z.M.; manuscript writing, S.Y. and L.M.; literature search and data collection, Q.S. and S.Y.; research design, J.W. and G.C.; data collection and literature search, J.W. and G.C.; writing-draft preparation, S.Y. and L.M.; data analysis and software used, Z.M. and L.M.; finalize the version to be published and revise the manuscript, M.L. and L.M. All authors have read and agreed to the published version of the manuscript.

Funding: This research was funded by the Provincial Education Department Fundamental Research Project, China, grant number 2020-KYYWF-0243.

Data Availability Statement: Data available in a publicly accessible repository.

Acknowledgments: The authors would like to thank Minghui Zhuang for excellent technical support and Jungang Li for critically reviewing the manuscript.

Conflicts of Interest: The authors declare no conflict of interest. 


\section{References}

1. Meseguer-Olmo, L.; Vicente-Ortega, V.; Alcaraz-Baños, M.; Calvo-Guirado, J.L.; Vallet-Regí, M.; Arcos, D.; Baeza, A. In vivo behavior of Si-hydroxyapatite/polycaprolactone/DMB scaffolds fabricated by 3D printing. J. Biomed. Mater. Res. Part A 2013, 101, 2038-2048. [CrossRef] [PubMed]

2. Mu, L.T.; Ma, Z.; Wang, J.Y.; Yuan, S.D.; Li, M.Q. Corrosion behavior and biological activity of micro arc oxidation coatings with berberine on a pure magnesium surface. Coatings 2020, 10, 837. [CrossRef]

3. Hu, Y.L.; Wang, Z.Q.; Ai, J.Y.; Bu, S.C.; Liu, H.W. Preparation of coating on the titanium surface by micro-arc oxidation to improve corrosion resistance. Coatings 2021, 11, 230. [CrossRef]

4. Nurettin, S.Z.; Zafer, E.V.; Said, M.K. Review of magnesium-based biomaterials and their applications. J. Magnes. Alloy. 2018, 6, 23-43.

5. Bakhsheshi, H.R.; Hamzah, E.; Ismaii, A.F. In vitro degradation behavior, antibacterial activity and cyto-toxicity of TiO ${ }_{2}-$ $\mathrm{MAO} / \mathrm{ZnHA}$ composite coating on Mg alloy for orthopedic implants. Surf. Coat. Technol. 2018, 334, 450-460. [CrossRef]

6. Gill, P.; Munroe, N. Review on magnesium alloys as biodegradable implant materials. Int. J. Biomed. Eng. Technol. 2012, 10, 383. [CrossRef]

7. Fierascu, I.; Fierascu, I.C.; Dinu-Pirvu, C.E.; Fierascu, R.C.; Anuta, V.; Velescu, B.S.; Jinga, M.; Jinga, V. A Short Overview of Recent Developments on Antimicrobial Coatings Based on Phytosynthesized Metal Nanoparticles. Coatings 2019, 9, 787. [CrossRef]

8. Janning, C.; Willbold, E.; Vogt, C.; Nellesen, J.; Lindenberg, A.M.; Windhagen, H.; Thorey, F.; Witte, F. Magnesium hydroxide temporarily enhancing osteoblast activity and decreasing the osteoclast number in peri-implant bone remodelling Acta Biomater. Acta Biomater. 2010, 6, 1861-1868,. [CrossRef]

9. Zhang, R.F.; Zhang, Z.Y.; Zhu, Y.Y.; Zhao, R.F.; Hang, Z.; Shi, F. Degradation resistance and in vitro cytocompatibility of iron-containing coatings developed on WE43 magnesium alloy by micro-arc oxidation. Coatings 2020, 10, 1138. [CrossRef]

10. Draxler, J.; Martinelli, E.; Weinberg, A.; Zitek, A.; Irrgeher, J.; Meischel, M.; Stanzl, S.E.; Mingler, B. The potential of isotopically enriched Magnesium to study bone implant degradation in vivo. Acta Biomater. 2017, 51, 526-536. [CrossRef] [PubMed]

11. Sealy, M.P.; Guo, Y.B.; Caslaru, R.C.; Sharkins, J.; Feldmanet, D. Fatigue performance of biodegradable magnesium-calcium alloy processed by laser shock peening for orthopedic implants. Int. J. Fatigue 2016, 82, 428-436. [CrossRef]

12. Alessandro, M.; Lorella, C.; Carla, M.; Alessandro, B. Influence of plasma electrolytic oxidation on fatigue behaviour of ZK60A-T5 magnesium alloy. Coatings 2020, 10, 1180-1191.

13. Razavi, M.; Fathi, M.; Savabi, O.; Vashaee, D.; Tayebi, L. Regenerative influence of nanostructured bredigite (Ca7MgSi4O16)/anodic spark coating on biodegradable AZ91 magnesium alloy implants for bone healing. Mater. Lett. 2015, 155, 97-101. [CrossRef]

14. Rzychon, T.; Kiełbus, A. Microstructure of WE43 casting magnesium alloy. J. Achiev. Mater. Manuf. Eng. 2007, $21,31-34$.

15. Yan, T.; Tan, L.; Xiong, D.; Liu, X.; Ke, Y. Fluoride treatment and in vitro corrosion behavior of an AZ31B magnesium alloy. Mater. Sci. Eng. C 2010, 30, 740-748. [CrossRef]

16. Yan, T.; Tan, L.; Xiong, D.; Zhang, B.; Yang, K. A manganese oxide contained coating forbiodegradable AZ31B magnesium alloy. Surf. Rev. Lett. 2009, 16, 533-538. [CrossRef]

17. Lu, Y.; Wan, P.; Tan, L.; Yang, K.; Lin, J. Preliminary study on a bioactive Sr containing Ca-P coating on pure magnesium by a two-step procedure. Surf. Coat. Technol. 2014, 252, 79-86. [CrossRef]

18. Hoehlinger, M.; Heise, S.; Wagener, V.; Boccaccini, A.R.; Virtanen, S. Developing surface pre-treatments for electrophoretic deposition of biofunctional chitosan-bioactive glass coatings on a WE43 magnesium alloy. Appl. Surf. Sci. 2017, 405, 441-448. [CrossRef]

19. Golshirazi, A.; Kharaziha, M.; Golozar, M.A. Polyethylenimine/kappa carrageenan: Micro-arc oxidation coating for passivation of magnesium alloy. Carbohydr. Polym. 2017, 167, 185-195. [CrossRef] [PubMed]

20. Wang, J.Y.; Li, M.Q.; Zhang, D.Q.; Peng, S.H. Corrosion resistance and cell compatibility in vitro of Chinese herbal extract coating on magnesium. Results Phys. 2019, 12, 1465-1474. [CrossRef]

21. He, F.P.; Chen, Y.; Li, J.Y.; Lin, B.M.; Yi, O. Improving bone repair of femoral and radial defects in rabbit by incorporating PRP into PLGA/CPC composite scaffold with unidirectional pore structure. J. Biomed. Mater. Res. Part A 2015, 103, 1312-1324. [CrossRef] [PubMed]

22. Dan, M.; Dong, L.; Ying, W. Effects of adding resorbable chitosan microspheres to calcium phosphate cements for bone regeneration. Mater. Sci. Eng. C 2015, 47, 266-276.

23. Huang, J.G.; Pang, L.; Chen, Z.R.; Tan, X.P. Dual-delivery of vancomycin and icariin from an injectable calcium phosphate cement-release system for controlling infection and improving bone healing. Mol. Med. Rep. 2013, 8, 1221-1227. [CrossRef] [PubMed]

24. Li, J.N.; Cao, P.; Zhang, X.N. In vitro degradation and cell attachment of a PLGA coated biodegradable Mg-6Zn based alloy. J. Mater. Sci. 2010, 45, 6038-6045. [CrossRef]

25. Zeng, X.; Xiong, S.; Zhuo, S.; Liu, C.; Miao, J.; Liu, D.; Wang, H.; Zhang, Y.; Zheng, Z.; Ting, K.; et al. Nanosilver/poly (dl-lactic-co-glycolic acid) on titanium implant surfaces for the enhancement of antibacterial properties and oste-oinductivity. Int. J. Nanomed. 2019, 14, 1849-1863. [CrossRef] [PubMed]

26. Cai, Y.L.; Zhang, X.C. Protective effect of Rhizoma drynariae extract on osteoporosis in ovariectomized rat model. Trop. J. Pharm. Res. 2016, 15, 1447. [CrossRef] 
27. NilamberLal Das, R.; Muruhan, S.; Nagarajan, R.P. Naringin prevents ultraviolet-Bradiation-induced oxidative damage and inflammation through activation of peroxisome proliferator-activated receptor $\gamma$ in mouseembryonic fibroblast (NIH-3T3) cells. J. Biochem. Mol. Toxicol. 2019, 33, 2263-2273. [CrossRef]

28. Cui, L.Y.; Gao, S.D.; Li, P.P.; Zeng, R.C.; Zhang, F.; Li, S.Q. Corrosion resistance of a self-healing micro-arc oxidation/poly methyltrimeth oxysilane composite coating on magnesium alloy az31. Corros. Sci. 2017, 118, 84-95. [CrossRef]

29. Batra, U.; Kapoor, S.; Sharma, S. Influence of Magnesium Ion Substitution on Structura land Thermal Behavior of Nanodimensional Hydroxyapatite. J. Mater. Eng. Perform. 2013, 22, 1798-1806. [CrossRef]

30. Diana, M.V.; Ionut, C.I.; Elena, U. Magnesium doped hydroxyapatite-based coatings obtained by pulsed galvanostatic electrochemical deposition with adjustable electrochemical behavior. Coatings 2020, 10, 2-17.

31. Hofmeister, A.M.; Keppel, E.; Speck, A.K. Absorption and reflection infrared spectra of $\mathrm{MgO}$ and other diatomic compounds. Mon. Not. R. Astron. Soc. 2003, 345, 16-38. [CrossRef]

32. Kharaziha, M.; Fathi, M.H. Synthesis and characterization of bioactive forsterite nanopowder. Ceram. Int. 2009, 35, 2449-2454 [CrossRef]

33. Liu, J.; Lu, J.F.; Kan, J.; Jin, C.H. Preparation, characterization and antioxidant activity of phenolic acids grafted carboxyme-thyl chitosan. Int. J. Biol. Macromol. 2013, 62, 85-93. [CrossRef] [PubMed]

34. Cheng, S.; Wei, D.Q.; Zhou, Y. Mechanical and corrosion resistance of hydrophilicsphene/titania composite coatings on titanium and deposition and release of cefa-zolin sodium/chitosan films. Appl. Surf. Sci. 2011, 257, 2657-2664. [CrossRef]

35. Prabhu, K.; Karar, P.K.; Hemalatha, S. Isolation of chlorogenic acid from the stems of Viburnum coriaceum Blume. Pharm. Sin. 2011, 2, 87-92.

36. Cheng, Z.J.; Zhang, L.; Zhao, H.M. Spectroscopic Investigation of the Interactions of Cryptotanshinone and Icariin with Two Serum Albumins. J. Solut. Chem. 2013, 42, 1238-1262. [CrossRef]

37. Lin, X.; Tan, L.; Wan, P.; Yu, X.; Yang, K.; Hu, Z.; Li, Y.; Li, W. Characterization of micro-arc oxidation coating post-treated by hydrofluoric acid on biodegradable ZK60 magnesium alloy. Surf. Coat. Technol. 2013, 232, 899-905. [CrossRef]

38. Taheri, M.; Kish, J.R.; Birbilis, N. Towards a physical description for the origin of enhanced catalytic activity of corroding magnesium surfaces. Electrochim. Acta 2014, 116, 396-403. [CrossRef]

39. Liu, H.; Li, W.L.; Luo, B.H.; Chen, X.; Wei, W.; Zhou, C. Icariin immobilized electrospinning poly(L-lactide) fibrous membranes via polydopamine adhesive coating with enhanced cytocompatibility and osteogenic activity. Mater. Sci. Eng. C 2017, 79, 399-409. [CrossRef]

40. Pozzo, L.Y.; Conceição, T.F.; Spinelli, A. Chitosan coatings crosslinked with genipin for corrosion protection of AZ31 magne-sium alloy sheets. Carbohydr. Polym. 2018, 181, 71-77. [CrossRef]

41. Vaz, J.M.; Taketa, T.B.; Hernandez, M.J. Antibacterial properties of chitosan-based coatings are affected by spacer-length and molecular weight. Appl. Surf. Sci. 2018, 445, 478-487. [CrossRef]

42. Mousa, H.M.; Lee, D.H.; Park, C.H. A novel simple strategy for in situ deposition of apatite layer on AZ31B magnesium alloy for bone tissue regeneration. Appl. Surf. Sci. 2015, 351, 55-65. [CrossRef]

43. Peng, S.H.; Li, M.Q.; Wang, J. Corrosion behavior and biological activity of micro-arc oxidation coating with puerarin on pure magnesium surface. Results Phys. 2019, 12, 1481-1489. [CrossRef] 